\title{
Designs for the Global South: a sustainable primary school in Uganda
}

\author{
M. Garrison \\ School of Architecture, University of Texas at Austin, USA
}

\begin{abstract}
In the summer of 2011 Robin Young-Ellis, a philanthropist, humanitarian, businesswoman and a board member of the non-profit group "Hope4Kids International" contacted the School of Architecture, the University of Texas at Austin (UTSoA) seeking design assistance for a new rural primary school in Uganda. In response to her challenge UTSoA graduate students, Kaziah Haviland, Amarantha Quintana-Morales, Carrie Joynton, Todd Mattocks, Greg Montgomery, Rachel Bullock, Brian Doherty and their faculty advisor, Professor Michael Garrison, formed a student group called Texas Impact Design. Texas Impact Design was founded to design a new rural primary school in Uganda that would promote regional sustainable design as an example for rural school development. Our research found many challenges facing Uganda, including poverty and unemployment, inadequate infrastructure, inadequate funding and financial services, gender issues and poor social services, especially health and quality education. This paper will describe the Texas Impact Design of a proposed Busia Primary School in rural Uganda.
\end{abstract}

Keywords: ecological, social and cultural sensitivity.

\section{Introduction}

In our proposed new primary school, with the ability to read and write children will become educated in agricultural practices that will help to improve the food supply. They will learn to negotiate a fair price for their crops, how to market their crafts, understand the importance of hygiene and how to prepare food and water that is free of harmful bacteria. The children and residents of the Busia District village will be educated in crop production; water from the well will allow them 
to irrigate and increase crop yields and revenue from the sale of excess crops will be used to sustain the school.

We fully admit to being naïve about building a new school in Uganda and that our view of Uganda is seen through our western lens. We have not lived in Africa and we do not pretend to know all the problems and opportunities that a builder of a new school from Africa would know. However, because we are young and naïve we were not shy about proposing new and different environmental and sustainable ideas for designing the school.

\section{Design process}

\subsection{Goals}

We made it a priority to ask the students and teachers of the School what they needed in a classroom. As a result three main goals were collaboratively established to create a new school. The first was to establish a small carbon footprint by using local materials and passive energy strategies. The second was to implement and encourage safety and secure building practices. And the third was to involve the residents of the local village directly in the design and construction of the school.

Following these goals we have developed a "green build" complex that is fully sustainable, is naturally lit, naturally ventilated and will be constructed using local building materials and hand-built construction techniques. We agree that the goal of the school design should be about sustainable design and not dependency. Therefore it is imperative that the young members of the village mix the sand and grasses, which will become building blocks, dig the foundation and carry the rocks to fill the trenches. The women and older children should assist in stacking the brick and carry food and water to the workers. The entire village will be part of the project so that the culture of the people will be embedded in the school.

\subsection{Concepts}

All students learn and absorb information differently. It is our concept to engage and inspire the students spatially while providing them with a variety of learning environments. We addressed this issue by creating several different learning zones. In our communication with the local leaders of the primary school, we learned that they would prefer a better student-teacher ratio. This led us to break up the classroom into different zones in order to have the potential for small groups of learning. The most prominent space in the school complex is the instructor-led classroom space. In this space, we gave visual priority to the chalkboard and teaching area, maximized ambient light and ventilation, and accounted for acoustical challenges. "Smart-wall" bookcases and corkboards between adjoined classrooms allow for books and a pin-up space while also serving as acoustic panels, minimizing sound transmission and sound reflectivity in the classrooms. 




Figure 1: Interior of proposed Busia District School classroom.

\section{Sustainable design}

\subsection{Sustainable building systems}

Most people living in rural Uganda depend on collected wood for cooking and preparing drinking water. A rapidly increasing human population combined with rapidly disappearing forest patches is intensifying pressure on the Uganda's resources. Children are the main collectors of fuel wood and will also be most impacted in the future by the emerging local energy crisis. The Texas Impact Design team therefore believes that schools are an excellent starting point for teaching about regional sustainable building systems and renewable energy alternatives.

The climatic design of the new primary school was driven by local circumstances such as the orientation of the site, the people's living conditions, their construction skills, access to local materials, etc. Special attention has been given to eco-friendly design measures including, shading verandas, natural ventilation, daylighting, and the recycling of rainwater. We became an advocate of the establishment of an ecological school design so that integration of innovative sustainable design and construction systems with available local resources was a key concern for the design and construction of the school. Taking advantage of the great potential of traditional materials and renewable energy resources and recyclable waste products in the design and construction was a major focus of our study and provided a useful model for the design of the school. 


\subsection{Local building materials}

It is our goal to minimize the energy consumed by the school as it serves to educate the community about green building strategies. We have accomplished this by proposing construction based on local materials, which, include bricks, made onsite, locally and sustainably harvested wood, and locally manufactured windows and sheet metal. Using the hydra-form brick-making machine, bricks are to be made on site using primarily local earth. The local community can craft the wood detailing. Other building materials, such as window shutters, sheet metal, and hardware will be bought locally, supporting Ugandan industries.

\subsection{Passive energy strategies}

Passive energy strategies incorporated in the classroom include a passive lighting design, passive ventilation, thermal mass, shading, and rainwater collection. Due to Uganda's equatorial location, the sun is directly overhead for most of the year. Proposed clearstory lighting allows for maximum ambient light to enter the classroom without the harsh glare and heat caused by direct equatorial sunlight. The windows are situated in order to maximize natural ventilation, flushing the hot air out of the classroom with prevailing winds. The ceiling is designed to absorb radiant heat from the metal roof, eliminating unwanted heat gain into the classrooms. The thermal mass provided by the masonry walls also helps to keep the building cool. Rainwater is to be collected from the metal roof of the classrooms and can be used to irrigate the agricultural fields.

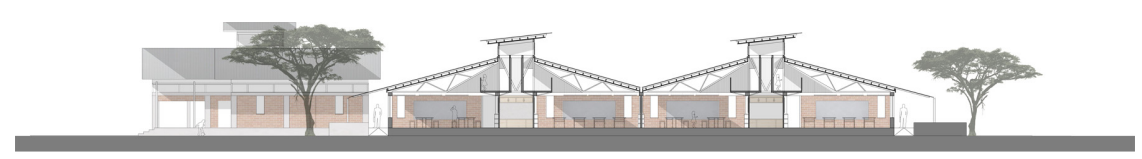

Figure 2: Section of proposed Busia District School classroom.

\subsection{Permaculture}

Feeding and educating students through a system of aquaculture, slow drip irrigation, and permaculture are at the core of the educational and the sustainable agriculture mission of the school. Children in Uganda often are not properly fed, and nutrition is a primary issue in the health and growth of primary school aged children. The school proposes to integrate sustainable agricultural practices into the curriculum. This will enable the school to provide food for all of the students, and it will teach valuable skill, responsibilities and healthy living.

Using drip irrigation, mulching heavily and tenting beds with shade cloth for shading are all techniques that could be employed to ensure successful plant production in the warm climate of Uganda. Aquaculture has the potential to be utilized as an alternative source of animal protein supply in rural areas of Uganda. 


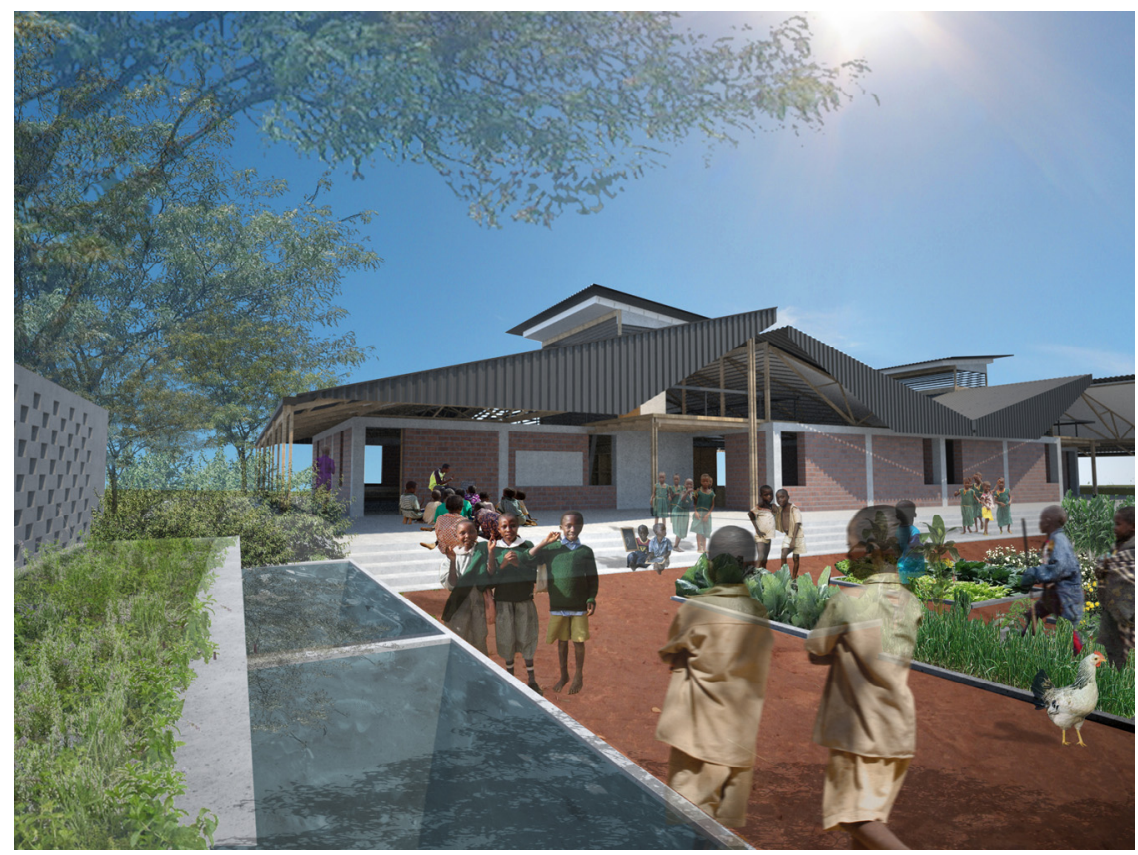

Figure 3: School courtyards based on teaching permaculture.

Aquaculture can contribute to human food security either by supplying protein to people or by increasing income and thus increasing the capacity to purchase food on the market. Fishery food products are a potential answer to the growing problem of dietary animal-protein shortages. Fish are able to convert their feed into flesh about two times more efficiently than chickens and five to ten times more efficiently than beef cattle. Feed conversion rates of fish are higher than other common commercial animal protein sources because: (a) fish can utilize foods that are not used by most land animals; and (b) they require less energy from their foods to live. Moreover, fish can use the entire three-dimensional environment of water tanks, from top to bottom and sideways, for living space, while terrestrial animals are confined to the two-dimensional surface of the ground. Consequently, the proper combination of fish species, adequate fertilizations, and careful feeding can result in yields approaching 6,250 pounds per acre compared to approximately 1,000 pounds per acre yield from beef cattle production. The potential for commercial production and the lure of high profits have accelerated the interest in fish farming and other types of aquaculture. Aquaculture fish farming requires fish feeding. Commercial fish feeds, tailored to the individual needs of specific fish breeds, are available but expensive, and some fish, such as Tilapia, will thrive on algae and grass clippings along with small doses of animal manure. Excess fish, fruit and vegetables not consumed by the school can be sold to generate funding for garden and school maintenance and equipment promoting a sustainable food production system. 

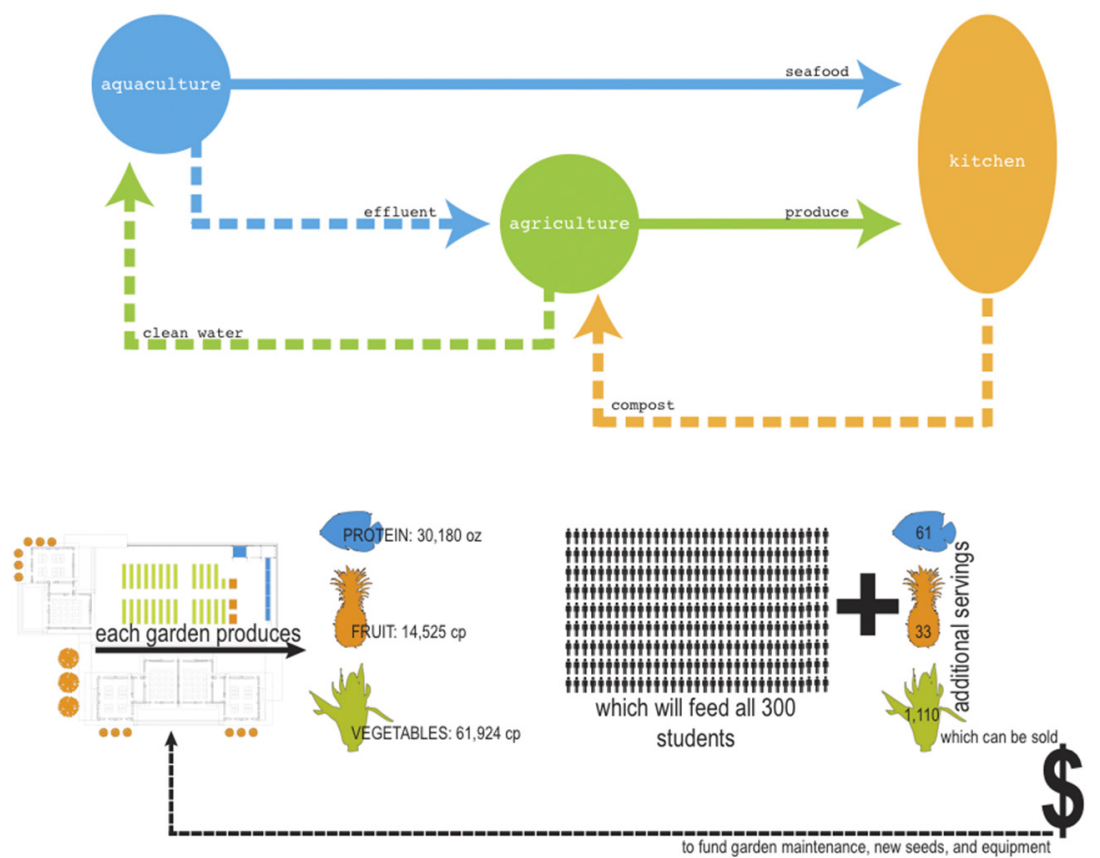

Figure 4: Permaculture.

\section{Integrity}

\subsection{Safety and security}

It is our goal to encourage safety and secure building practices with the classrooms. Through the use of properly designed foundation and roof systems, as well as load-bearing masonry walls, we hope to illustrate proper building techniques in a building with structural integrity. We have also addressed the issue of security. Many Ugandan buildings have security systems, which include metal bars permanently installed in all windows and doors. Because this is a dangerous fire hazard to building occupants, we designed a security system, which is operable, providing needed security at night, with the openness for comfort and fire safety during the day. All Security panels slide on tracks to accommodate for these changing safety issues throughout the day. Another safety issue addressed in our classroom is an insect screen system, which will keep venomous snakes, spiders, and malaria-carrying mosquitoes out of the buildings.

\subsection{Community}

More than just a building to accommodate the basic education needs, the school will actively promote discovery, self-sufficiency and strong community 
relationships through an architecture that invites everyone in the village to engage in active learning. Classrooms will double as public spaces for community classes, civic events, and performances. Outdoor learning gardens will teach sustainable agriculture and nutritional practices, providing opportunities for collaborative interaction extending beyond the classroom walls.

The site strategy is another learning zone. The adjacent covered outdoor terraces can serve as shaded outdoor classrooms or as play areas, abutting the proposed agricultural fields. Classrooms will be organized around gathering spaces of various scales, maximizing flexibility and creating safe outdoor spaces for learning, play, and community events. Phasing plans will allow the school to grow over time as it adapts to the school's future needs. A secure, welcoming entry will invite the community into a learning environment where the building is designed to teach in partnership with the school and the village community. Community input drives the design process, ensuring a school that is deeply embedded in the local culture and continued growth of the village. As an anchor to the community, the village school will invite inclusive ownership amongst the residents and provide a model of experiential community education for other villages and towns.

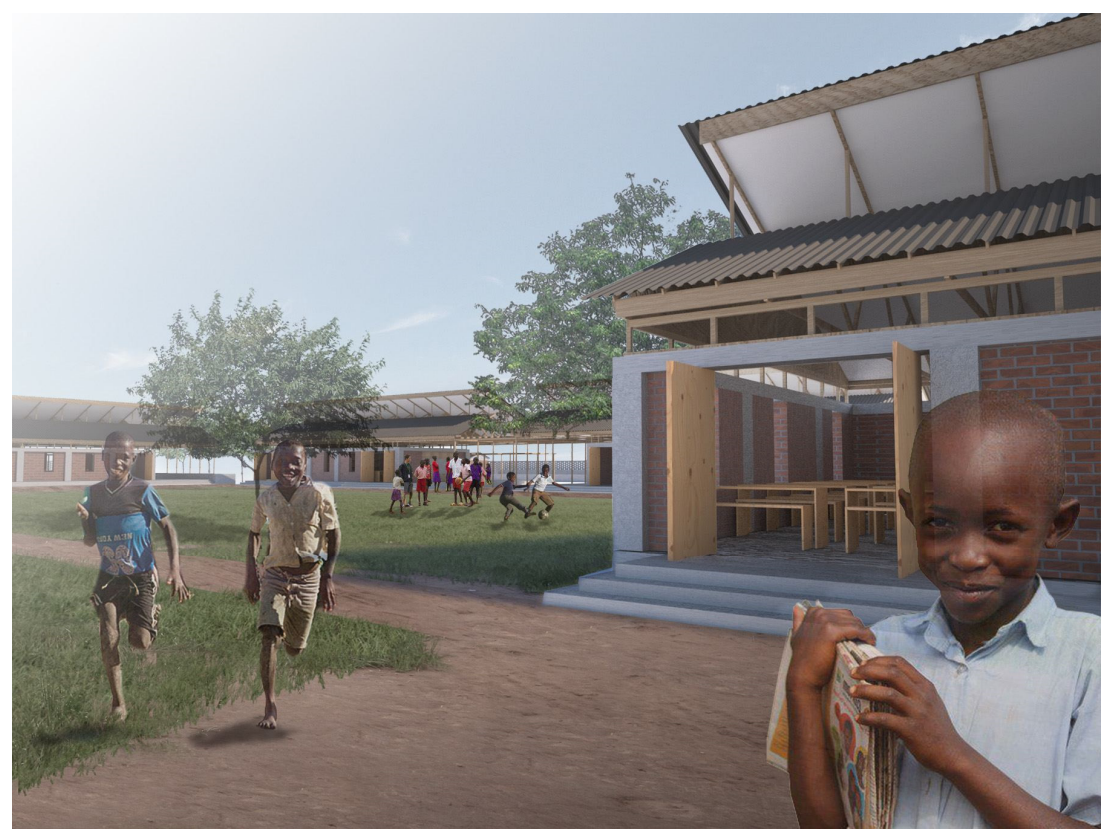

Figure 5: Busia District School community courtyards. 


\section{Conclusion}

While we started off, from our Texas based studio, investigating useful sustainable design approaches for Africa, somewhere during the process we developed a greater appreciation of the Ugandan people, their culture and their timeless way of building. We learned from them about their low environmental footprint and the opportunities for sustainable design we could apply to our projects in Central Texas, which also has a warm climate. Education and learning is a two way street and we learned as much from our design experience with the Ugandan village school as we have provided in the design of the school. And we have also learned about the value of education.

Any student, no matter where they are born, should have the opportunity to attend school. Basic education is a critical part of rural development. Individuals who have had some education are better farmers and more capable of finding offfarm employment. The rural villages also benefit from the overall development of an improved economy and the alleviation of poverty, in which basic education is essential. The benefits to the school children of a high quality education are selfevident, however, the real benefits of the school are long term for the community. Currently, there are almost no rural Ugandan professionals as the quality of primary education has been too poor to allow access to good secondary schools and universities. The long term benefit of the school will be the new generation of well-educated children who eventually come back to help their community as leaders, teachers, doctors, builders, engineers, and architects.

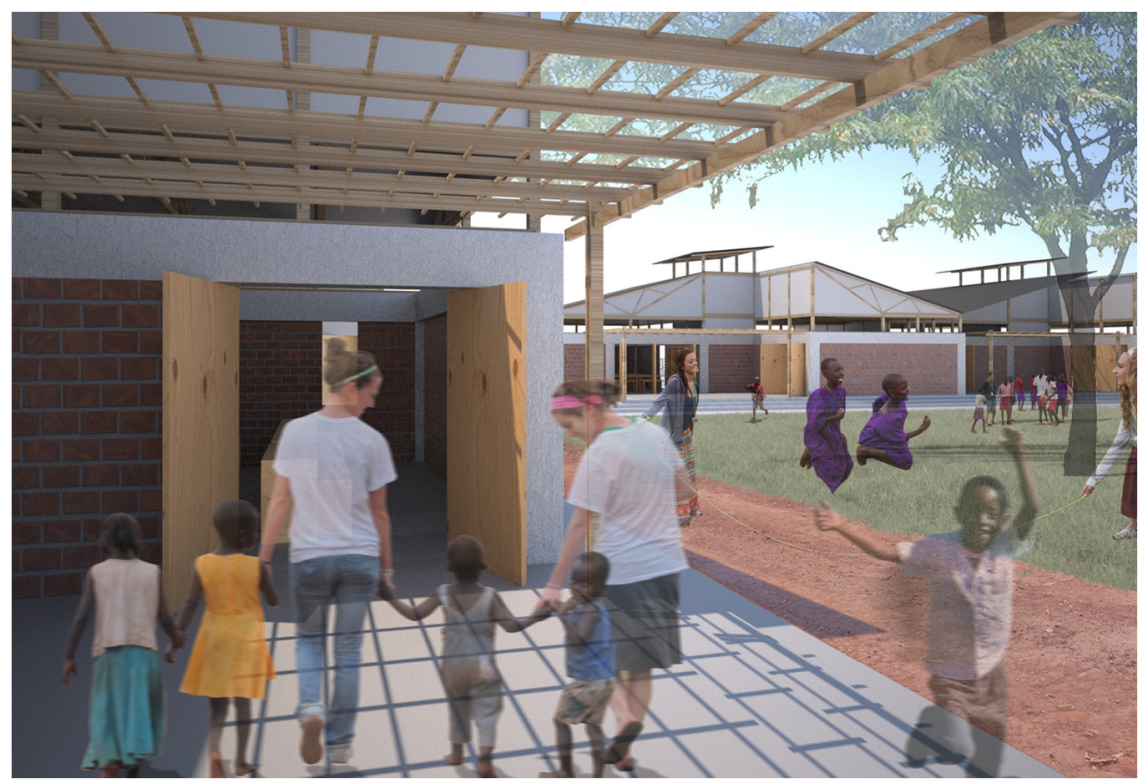

Figure 6: Busia District School. 


\section{References}

[1] Huang, H.K., (1994) Computer Simulation Analysis of Biological and Agricultural Systems, CRC Press, Ann Arbor, Michigan.

[2] Kwok, A., (2009) Zero Net Energy Workshop and Design Charrette, The University of Oregon Department of Architecture and the Center for Housing Innovation, Portland, Oregon.

[3] Nannyonjo, H., (2007) Education Inputs in Uganda: An Analysis of Factors Influencing Learning Achievement in Grade Six, World Bank Working Paper No 98, Washington D.C.

[4] Mazria, E., (1980) The Passive Solar Energy Book: A Complete Guide to Passive Solar Home, Greenhouse and Building Design, Rodale Press, Emmaus, Pennsylvania.

[5] Mulkeen, A.G. and Higgins, (2009) Multi-grade Teaching in Sub-Saharan Africa: Lessons from Uganda, Senegal, and The Gambia, World Bank Working Paper No. 173, Washington D.C.

[6] Stout R. and Garrison M., (2004) Building Envelope, National Council of Architectural Registration Boards, Washington D.C. 